\section{PEMANFAATAN LIMBAH \\ KERAMIK (TILE) UNTUK \\ PENGEMBANGAN PRODUK \\ ELEMEN MOSAIC PADA DINDING \\ (Studi kasus pada usaha kecil Mozaik di \\ Cimahi)}

\author{
Deden Maulana \\ Program Studi Desain Komunikasi Visual, \\ Universitas Pembangunan Jaya \\ dedenmaulanan@gmail.com
}

\begin{abstract}
Abstrak
Mozaik, adalah perwujudan karya seni dimana bentuknya berupa susunan kepingkeping dari bahan tertentu, seperti; seperti dari batu, kaca, plastik, kayu dan seterusnya yang mempunyai unsur warna serta dapat dibentuk sedemikian rupa menjadi sebuah karya visual.

Model bentuk seni mozaik ini bukanlah hal yang baru, karya seni mozaik telah lama diketemukan sebagai elemen estetis yang banyak ditempatkan pada dinding ruang, seperti; pada bangunan tempat peribadatan, ruang pertemuan serta beberapa rumah yang kini banyak diketemukan pada bangunan heritage.

Pada masa sekarang, pemodelan karya mozaik ini telah banyak diadopsi menjadi kebutuhan elemen estetik untuk penataan dekorasi interior pada perumahan, seperti ; penataan mozaik pada dinding rumah, resort, apartemen, hotel dan seterusnya. Penerepan mozaik juga dapat dilakukan di
\end{abstract}

luar ruang atau eksterior guna melengkapi keindahan taman.

Model pendekatan dari penelitian ini adalah bentuk eksperimen yaitu untuk mencari dan menciptakan menciptakan bentuk, serta konfigurasi susunan warna baru dari limbah potongan keramik yang tersedia dari hasil pabrikan. Tujuan dari penelitian eksperimen ini adalah memanfaatkan sisa potongan keramik dari hasil limbah menjadi bentuk yang lebih bermanfaat.

Kata kunci: Art, Design, Etnic, Mosaic, Modular, Pixelite, Material, Production technical

\section{Abstract}

Mozaics, are a form of art where it is made out of small peces of shards made from certain materials like rock,glass,plastic or wood that have an element of colour and can be formed to make a visual form of art.

Mozaics are not a new form of art, it can be found in many places such as religious places, meeting rooms and also houses and heritage buildings.

Nowadays mozaics are adopted as an aesthetic element for interior decoration in homes, resorts, apartments and so on. The application of mozaics can also be applied to exterior places to add more beuty to parks. 
The research methods used will be experimental to find a form and shape that is using the ceramics waste so that it can be more usefull than just be waste.

Keyword: Art, Design, Etnic, Mosaic, Modular, Pixelite, Material, Production technical

\section{PENDAHULUAN}

\subsection{Latar Belakang}

Sisa limbah dari potongan keramik dari hasil produk pabrik yang tidak terpakai atau rijek sangatlah banyak jumlahnya, terlebih disuatu tempat yang berdekatan dengan pabrik keramik (tile). Biasanya potongan keramik tersebut langsung dibuang sebagai timbunan tanah. Kalau di hitung jumlah kubikasi sangat banyak, hal itu baru limbah dari pabrik sebagai produk rijek, belum lagi limbah dari developer property yang cerderung terus meningkat.

Kenapa dibuang tidak di daur ulang ?, karena dimana keramik (tile) tersebut mempunyai unsur lapisan kaca (glasure) yang telah mengalami proses pembakaran diatas 1200 derajat cecius sehingga tidak mudah untuk di urai kembali. Hampir kebanyakan keramik yang dihasilkan oleh pabrik mempunyai daya ketahanan tertentu atas hasil uji coba yang sangat baik untuk kegunaan dan kenyamanan konsumen sehingga keberadaannya tersebut di buat sedemikian rupa menjadi lebih kuat.

Dari banyaknya limbah yang melimpah serta kurangnya kepedulian terhadap itu maka perlu dilakukan kajian untuk menangani sisa dari potongan keramik menjadi suatu produk yang dapat dimanfaatkan keberadaannya.

Penelitian akan dilakukan secara bertahap sesuai metode atau cara-cara dalam proses perancangan untuk menciptakan suatu produk. Dilakukan sacara mendasar adalah melakukan pemetaan terhadap sisi bahan keramik (tile) tersebut dari berbagai aspek, tujuan serta manfaat yang akan dijadikan elemen dinding dalam bentuk mosaic.

Kajian terhadap limbah keramik yang diangkat menjadi tema penelitian sangatlah jarang hal ini menunjukan kepedulian terhadap limbah dari hasil pabrikan kurang mendapat perhatian, barangkali hal ini beranggapan akan sangat kurang kebermanfaatan yang akan diperoleh dari limbah tersebut.

Dengan hasil penelitian ini maka akan diperoleh suatu produk mosaic yang didapat dengan material limbah keramik dengan berbagai corak, warna serta ragam hias yang akan menjadi alternatif dalam mengembangkan produk seni yang dapat dipergunakan sebagai pengisi dekorasi pada suatu ruang. 


\subsection{Rumusan Masalah}

Diketemukan beberapa permasalahan, diantaranya;

a. Melihat langsung mengenai keberadaan sisa potongan keramik (tile) dari hasil pabrik yang terbuang dalam jumlah cukup banyak.

b. Pemanfaatan bahan dari hasil pabrikan yang dapat di fungsikan kembali.

c. Model Eksperimen bentuk Mozaik pada dinding.

d. Model usaha kecil yang dapat dikembangkan.

Sisa limbah dari potongan keramik (tile) dari hasil produk pabrik yang tidak terpakai atau rijek sangatlah banyak jumlahnya, terlebih disuatu tempat yang berdekatan dengan pabrik keramik (tile). Biasanya potongan keramik tersebut langsung dibuang sebagai timbunan tanah. Kalau di hitung jumlah kubikasi sangat banyak, hal itu baru limbah dari pabrik sebagai produk rijek, belum lagi limbah dari developer property yang cerderung terus meningkat.

Kenapa dibuang tidak di daur ulang ?, karena dimana keramik (tile) tersebut mempunyai unsur lapisan kaca (glasure) yang telah mengalami proses pembakaran diatas 1200 derajat cecius sehingga tidak mudah untuk di urai kembali. Hampir kebanyakan keramik yang dihasilkan oleh pabrik mempunyai daya ketahanan tertentu atas hasil uji coba yang sangat baik untuk kegunaan dan kenyamanan konsumen sehingga keberadaannya tersebut di buat sedemikian rupa menjadi lebih kuat.

Dari banyaknya limbah yang melimpah serta tidak adanya kepedulian terhadap itu maka perlu dilakukan kajian untuk menangani sisa dari potongan keramik menjadi suatu produk yang dapat dimanfaatkan keberadaannya.

Penelitian akan dilakukan secara bertahap sesuai metode atau cara-cara dalam proses perancangan untuk menciptakan suatu produk. Dilakukan sacara mendasar adalah melakukan pemetaan terhadap sisi bahan keramik (tile) tersebut dari berbagai aspek, tujuan serta manfaat yang akan dijadikan elemen dinding dalam bentuk mosaic.

Kajian terhadap limbah keramik yang diangkat menjadi tema penelitian sangatlah jarang hal ini menunjukan kepedulian terhadap limbah dari hasil pabrikan kurang mendapat perhatian, barangkali hal ini beranggapan akan sangat kurang kebermanfaatan yang akan diperoleh dari limbah tersebut.

Dengan hasil penelitian ini maka akan diperoleh suatu produk mosaic yang didapat dengan material limbah keramik dengan berbagai corak, warna serta ragam hias yang akan menjadi alternatif dalam mengembangkan produk seni yang dapat 
dipergunakan sebagai pengisi dekorasi

pada suatu ruang.

\subsection{Tujuan dan Manfaat Penelitian}

\subsubsection{Tujuan}

a. Eksplorasi limbah keramik dengan memanfaatkan tren desain yang sedang berkembang untuk menghasilkan prototype produk mosaic dinding atau mural.

b. Menghasilkan teknik produksi baru dalam proses mengolah limbah keramik untuk diaplikasikan secara mudah oleh pengusaha IKM kerajinan mosaic di wilayah kota Cimahi dan sekitarnya. Mempublikasikan mengenai kepedulian lingkungan dari sisa limbah keramik yang dapat manfaatkan sebagai nilai estetik.

\subsubsection{Manfaat}

a. Menghasilkan suatu referensi desain dengan mengutamakan ciri khas lokal sehingga dapat meningkatkan mutu dan kualitas produk itu sendiri.

b. Menghasilkan variasi produk mosaic dari limbah keramik (tile). yang di olah agar ramah lingkungan.

c. Meningkatkan nilai tambah secara ekonomis dari limbah keramik yang terbuang dari hasil pabrikan, developer, membangun rumah, atau penadah penjual keramik " $\mathrm{kw}$

\section{KAJIAN PUSTAKA}

\subsection{Tinjauan Seni Mosaic}

Mosaik atau dalam bahasa Inggris berasal dari kata mosaic ( /mō'zā-ik/) yang merupakan kata benda dengan pengertian suatu gambar atau pola yang dihasilkan dengan penyusunan potonganpotongan kecil dan berwarna dari bahan seperti batu, keramik atau gelas. Memang saat ini kadang istilah mosaik juga digunakan dalam arti luas seperti dalam bidang lain yang diartikan sebagai pembentukan komposisi tunggal dari potongan-potongan yang lebih kecil. (Wikipedia)

Implementasi seni mosaic telah banyak dipakai untuk menghiasi kebutuhan ruang, terutama dipakai pada lantai dan dinding sebagai estetika dekorasi ruang. Hampir kebanyakan material mosaic menggunakan bahan yang cukup keras dan kuat karena difungsikan sebagai pelapis dari suatu permukaan, jadi seni mosaik selain berfungsi sebagai estetika ruang juga untuk kekuatan lapisan dinding.

Mosaik adalah kegiatan seni membuat gambar dengan menggunakan material tertentu dengan cara menempel atau menyusun dengan menggunakan bongkah atau potongan benda-benda kecil. Jika pengetiannya demikian maka produk 
mosaic dapatmenggunakan material lainnya selain keramik.

Mosaik dapat berupa teknik seni dekorasi atau suatu aspek dekorasi interior suatu bangunan. Potongan bahan berukuran kecil ini, umumnya berbentuk kotak, dari batu atau gelas dengan berbagai macam warna disebut sebagai tesserae (tessellae), yang kemudian digunakan untuk menyusun suatu pola atau membentuk suatu gambar.

Kini dalam perkembangan implementasi seni mosaik telah banyak diadaptasi oleh pabrikan dimana setiap pabrik keramik (tile) dapat menciptakan bentuk desain seni mosaik yang di buat secara mudah dalam jumlah masal, hal itu bisa kita sebut sebagai tiruan mosaic (reflica mosaic). Pada umumnya corak mosaik pabrikan mengarah pada pola atau corak kembali ke alam, seperti motif bebatuan, pasir atau lempengan lain yang terdapat di alam.

Sementara limbah dari limpahan pabrikan adalah berupa serpihan potongan keramik yang cukup banyak jumlahnya yang tidak dapat kita perhatikan. Walaupun demikian keramik yang disebut " $\mathrm{kw}$ itu dapat juga sebagian masyarakat dapat memanfaatkan sebagai fungsi lainnya sebagai lantai.

\section{URAIAN}

KEGIATAN, PEMBAHASAN DAN HASIL KEBARUAN

\subsection{Pengertian Mozaik}

Adalah karya seni yang terbuat dari kepingan atau bongkah material tertentu yang dapat dibuat menjadi suatu bentuk gambar/ visual. Kepingan tersebut telah mempunyai unsur warna sehingga dapat disusun manjadi suatu bentuk tertentu. Sedangkan material dapat terbuat dari, seperti batu, keramik, kaca, plastik dan kayu serta material lain yang dipergunakan sebagai rangkaian harmoni warna.
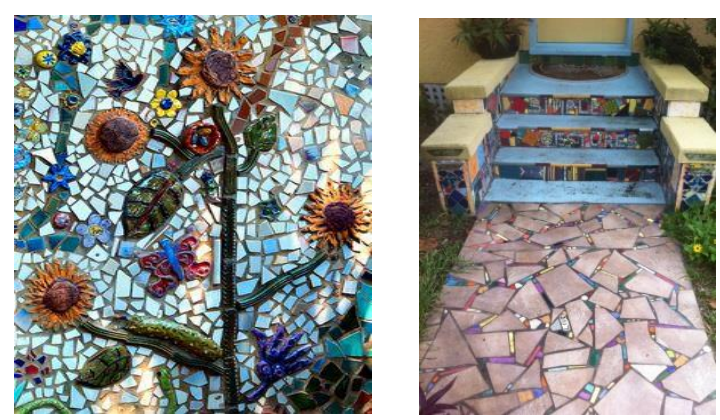

Gambar 1: Contoh mozaik dengan perpaduan warna yang beragam

\subsection{Fungsi Mozaik}

Mozaik banyak dipergunakan sebagai elemen dekorasi pada dinding ruang, seperti dinding rumah, tempat ibadah dan ruang pertemuan baik sebagai estetik ruang dalam maupun ruang luar. Selain sebagai fungsi dekorasi, mozaik juga di fungsikan sebagai nilai ukuran dan kebanggaan bagi penggunanya.

\subsection{Desain mozaik}

Dua hal yang sangat dominan, gaya (style) mozaik pertama; bergaya dekoratif, stilasi, naturalis dan yang kedua; dekoratif stilasi, 
geometris. Kedua gaya ini menjadi dasar inspirasi bagi para seniman dan desainer sampai saat ini. Sedangkan penggunaan warna pada estetik karya mozaik lebih banyak di sesuaikan dengan kebutuhan tren segmentasinya. Selain gaya dan warna yang melekat pada karya mozaik adalah juga disebut kepingan atau potongan, istilah sekerang dalam era teknologi komputer disebut pixel (fixelite)

Dari ketiga elemen desain diatas; gaya (style), warna (color) dan dengan bentuk (shape), mozaik melahirkan visualiasasi yang banyak memberi tema visual dan berkaitan erat dengan tema/judul; flora, fauna, mahluk hidup dan stilasi abstrak geometris.

\subsection{Identifikasi material keramik}

Jenis keramik (tile) bergaya mozaik yang banyak terjual di toko bangunan adalah standar pabrikasi mulai dari ukuran; $(2 \times 2$, $5 \times 5,10 \times 10,20 \times 20,20 \times 25,30 \times 30$ dan seterusnya $80 \times 80 \mathrm{~cm}$ ). Jenis; keramik buat lantai, dinding, luar atau taman. Motif; gloss, dof, tekstur dan interlock, serta merek (brand) pabrik. - Identifikasi ini di tekankan pada beberapa jenis keramik yang memungkinkan dapat di olah menjadi produk daur ulang. Setiap jenis keramik pabrik yang terbuang menjadi limbah potongan pada dasarnya dapat dibuat dan diolah menjadi produk mozaik.

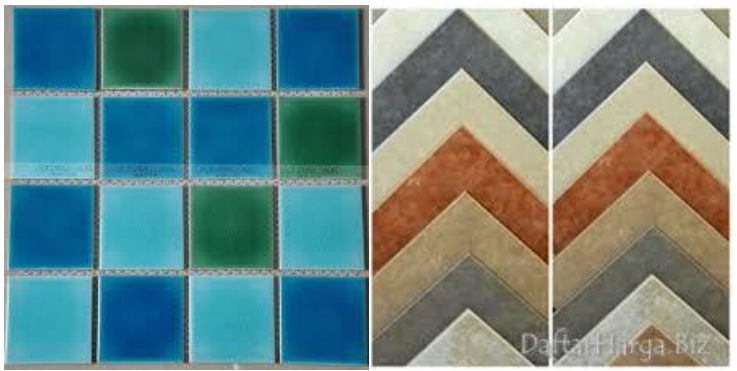

Gambar 2: Contoh tile keramik sebagai bahan dasar

Sumber: http://www.hargabangunan.xyz

\subsection{Klasifikasi material keramik}

Langkah berikutnya adalah melakukan klasifikasi dari material keramik berdasarkan atas; Ketebalan keramik (tile), warna dan corak tekstur, pemotongan ulang (cutting break). Klasifikasi material limbah dimaksud ini adalah untuk memudahkan dalam memilih bahan olahan sehingga akan menghasilkan suatu karya bentu yang lebih baik.

\subsection{Desain Mozaik}

Menentukan suatu konsep rancangan mozaik serta rencana aplikasi fungsi yang dapat berguna bagi estetik interior atau eksterior dalam suatu lingkungan atau hunian. Memberi konsep persepsi bahwa limbah keramik dapat dioptimalkan menjadi hal lebih bermanfaat. Memberi nilai ekonomis menjadi salah satu pengembangan ekonomi perseorangan atau kelompok. 


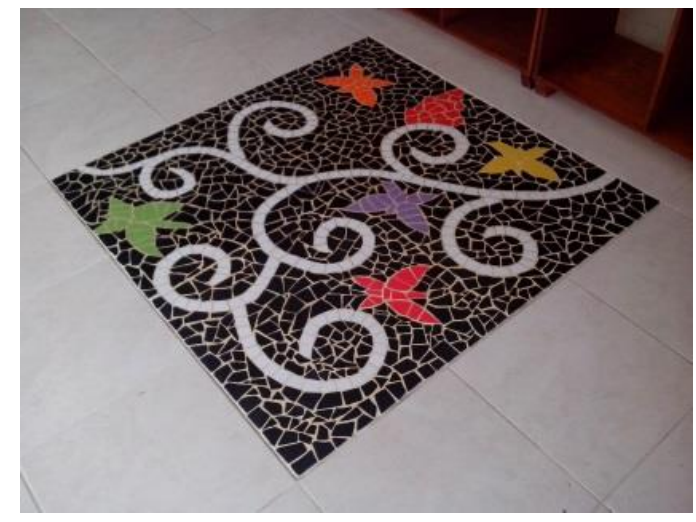

Gambar 3: Aplikasi penerapan mozaik tile.

\subsection{Persiapan Material}

Dapat dilakukan dengan cara mengikuti petunjuk dan tahapan proses sebagai berikut;

(1). Bahan dan kelengkapan ; a. Alas triplek - b. Plastik - c. Lem kayu - d. Semen putih/hitam - e. Air seperlunya- f. Tang potong - g. Batu asah - h. Lap tangan, maksker dan kaca mata - i. palu kecil. - y. ATK

(2). Keramik (tile) limbah yang sudah di klasifikasikan sesuai kebutuhan rancangan (3). Proses pembuatan dengan cara bertahap.

(4). Pengerjaan akhir

\subsection{Pengolahan dan Pembuatan Desain Mozaik.}

Adalah bagian dari proses yang dapat dilakukan dengan cara mengikuti petunjuk;

\section{Tahap pembuatan sketsa}

Pembuatan atau menuangkan gagasan/ ide dengan cara membuat sketsa/ pola gambar outline di atas lembaran kertas; penggambaran dapat dilakukan dengan banyak teknik, bisa dibuat secara freehand/ manual dengan tangan atau dengan cara menggunakan alat bantu tulis/ gambar lainnya.

Setelah pekerjaan membuat sketsa diatas kertas tadi selanjutnya kertas dilapisi dengan plastik dengan ukuran yang sama lebarnya dari ukuran kertas tersebut. Perhatikan lembaran kertas dan plastik tidak mengalami pergeseran. Lakukan pada meja dengan permukaan rata.

Pergunanakan grid (pola garis) sebagai bantuan bagi pemula.
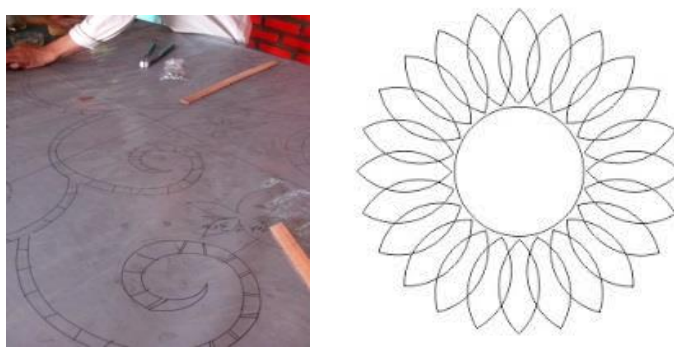

Gambar 4: Pembuatan sketsa/outline

\section{Tahap pemasangan mozaik}

Sebelum pemasangan mozaik keatas alas triplek, dipersiapkan kepingan keramik tile (cutting break) yang dapat di peroleh dari limbah yang sudah terpotong atau kita melakukan potongan lebih kecil.

Tahap penempelan dengan cara menyusun satu persatu bagian yang ditemplekan di atas pola gambar, penempelantersebut sampai menutupi seluruh pola gambar. 
Penempelan dilakukan dengan lem kayu, jika ada kesalahan pemasangan, untuk melepas tempelan tersebut pergunakan air panas dan teteskan pada tempelan tersebut.
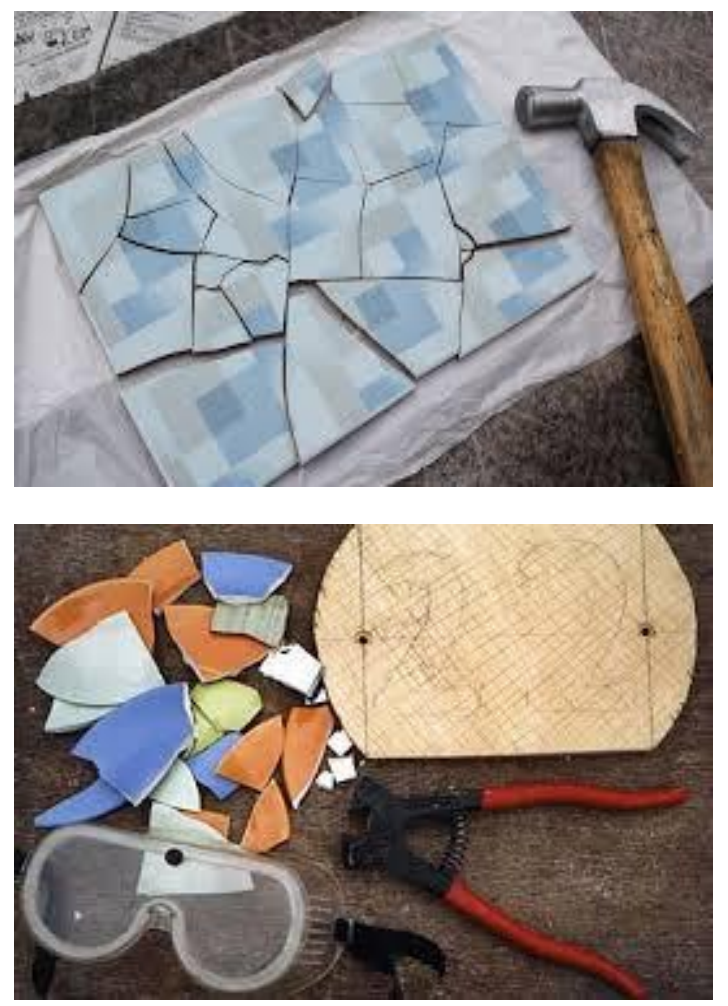

Gambar 5: Tahapan pemasangan mozaik

\section{Tahap finishing}

Dua hal yang mendasar dalam peerjaan akhir dari pembuatan mozaik keramik ini adalah; (1) dapat dilakukan dengan cara memberikan nat di sela-sela antara tempelan keramik tersebut, hal tersebut akan memberikan kesan kontras. (2) Tanpa menggunakan nat yaitu polos saja hal itu kan memberikan kesan lebih lembut atau natural jika nat terebut tersusun lebih rapat.

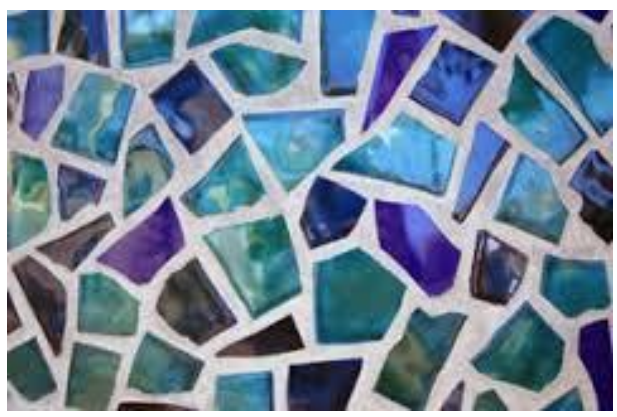

Gambar 6: Tahapan finishing dengan menggunakan nat

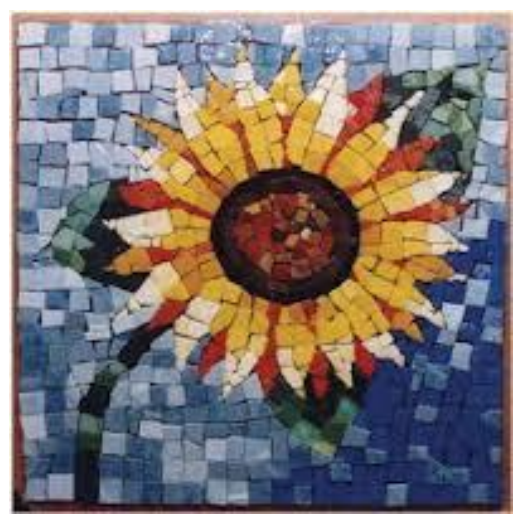

Gambar 7: Tahapan finishing tanpa menggunakan nat

\section{KESIMPULAN}

\subsection{Keluaran (Output) Hasil Riset}

a.Eksplorasi limbah keramik dengan memanfaatkan tren desain yang sedang berkembang untuk menghasilkan prototype produk mosaic dinding atau mural.

b. Menghasilkan teknik produksi baru dalam proses mengolah limbah keramik untuk diaplikasikan secara mudah oleh pengusaha IKM kerajinan mosaic di wilayah kota Cimahi dan sekitarnya.

c.Publikasikan mengenai kepedulian lingkungan dari sisa limbah keramik 
yang dapat manfaatkansebagai nilai estetik.

\subsection{Dampak (outcome) Hasil Riset}

a. Menghasilkan suatu referensi desain dengan mengutamakan ciri khas lokal sehingga dapat meningkatkan mutu dan kualitas produk itu sendiri.

b. Menghasilkan variasi produk mosaic dari limbah keramik (tile). yang di olah agar ramah lingkungan.

c. Meningkatkan nilai tambah secara ekonomis dari limbah keramik yang terbuang dari hasil pabrikan, developer, membangun rumah, atau penadah penjual keramik " $\mathrm{kw}$

\section{Daftar Pustaka}

1.Dermawan T. Agus . 1977. Seni rupa mosaik Soekanto. New York. Yayasan Seni Rupa AIA, 2009, Jakarta

2.Black, Sandy. 2011. Eco-Chic, The Fashion Paradox. Black Dog Publishing, Limited London, UK

3.Direktorat Jenderal Seni dan Budaya. 1999. Pedoman pembinaan dan pemanfaatan pesona seni kriya. Jakarta: Universitas Michigan 